\title{
Single-vessel synthesis of 5-hydroxymethylfurfural (HMF) from milled corn
}

Jonathan C. Overton ${ }^{1,2,3}$, Abigail S. Engelberth ${ }^{1,2,4^{*}}$, Nathan S. Mosier ${ }^{1,2,3}$

${ }^{1}$ Department of Agricultural and Biological Engineering, 225 South University Street, Purdue University, West Lafayette, IN, 47907

${ }^{2}$ Laboratory of Renewable Resource Engineering (LORRE), 225 South University Street, Purdue University, West Lafayette, IN, 47907

${ }^{3}$ Center for Catalytic Conversion of Biomass (C3Bio), 1203 W State Street, Purdue University, West Lafayette, IN, 47907

${ }^{4}$ Environmental and Ecological Engineering, 500 Central Drive, Purdue University, West Lafayette, IN, 47907

Supplementary information section consists of 7 pages containing three tables and two figures. 


\section{Experimental Section}

Reaction conditions and catalysts

DMSO, acetonitrile, maleic acid, and $\mathrm{AlCl}_{3}$ were purchased from SigmaAldrich (St. Louis, MO, USA). All reactions in this work were conducted at $180{ }^{\circ} \mathrm{C}$ with a maleic acid concentration of $0.05 \mathrm{M}$ and an $\mathrm{AlCl}_{3}$ concentration of $0.1 \mathrm{M}$. The reaction media included cosolvent concentrations of $20 \mathrm{vol} . \%$ DMSO and 40 vol. \% acetonitrile in water. Detailed methods regarding these reactions have been described previously. ${ }^{1,2}$ Briefly, Brønsted acids catalyze the hydrolysis of starch into the monosaccharide glucose. Glucose is then isomerized to fructose by $\mathrm{AlCl}_{3}$ (Lewis acid), followed by Brønsted acid-catalyzed dehydration of fructose to HMF. HMF can be further rehydrated to levulinic acid and each reaction in has parallel side reactions to undesired side products (humins). Figure S1 summarizes the reaction pathway. In all cases, substrate was loaded to at $30 \mathrm{wt} . \%$ and vigorously mixed before reacting. The substrates used were glucose, (Sigma Aldrich), starch (Sigma Aldrich), fermentation feed from a corn ethanol facility, and yellow dent corn milled to $1.375 \mathrm{~mm}$ (1/8 inch). All solid substrates were dried at 45 ${ }^{\circ} \mathrm{C}$ prior to use. Concentrations of reaction products were measured by high performance liquid chromatography as described in previous works. ${ }^{3}$ A Bio-Rad Aminex H column was used with a mobile phase consisting of 5\% acetonitrile and $10 \mathrm{mM}$ sulfuric acid. Components were detected by a refractive index detector (RID). Reference standards for quantification were created using pure chemical standards.

\section{Techno-economic analysis}

To perform an economic analysis, we designed an industrial process based on experimental data; the flow of material through the process is shown in Figure $\mathbf{3}$ in the manuscript. In the proposed process, corn kernels are received and dried before being passed through a hammer mill, 
producing particles with a mean size of $3.175 \mathrm{~mm}$. Ground corn is then mixed with a catalyst stream containing $0.05 \mathrm{M}$ maleic acid, $0.1 \mathrm{M}$ aluminum chloride, and $10 \mathrm{wt}$. \% sodium chloride dissolved in 40 vol. \% acetonitrile, 20 vol. \% DMSO, and 40 vol. \% water. Salt was added to facilitate downstream separation of HMF from the reaction mixture. ${ }^{4}$ The reactor has a retention time of three minutes and a temperature of $180^{\circ} \mathrm{C}$. Four reactors in parallel were employed to allow for continuous operation, with some reactors dedicated to reactions while the activated carbon in remaining reactors was stripped of HMF with diethyl ether (DEE). The outlet of the reactor exchanges heat with the reactor feed stream before being sent to a liquid-liquid extractor, where DEE is used to extract HMF. ${ }^{5}$ Experimental results indicate that 90 wt. \% of HMF can be recovered in the DEE stream. The partitioning of other components into DEE is assumed to be near ideal, where organic stream consists of $90 \%$ of feed $\mathrm{HMF}, 90 \%$ of feed acetonitrile, and DEE. All other components fully remain in the aqueous phase. DEE is then evaporated at $40{ }^{\circ} \mathrm{C}$ and $25 \mathrm{kPa}$, resulting in a pure HMF product stream; energy requirements for distillation were estimated using a multifrac column. DEE is condensed and recycled in a heat exchanger with the inlet stream of the evaporator to recover heat. Following extraction, the stream containing acetonitrile, DMSO, salt, and water undergoes fractional distillation to recover acetonitrile while concentrating DMSO and salt. All co-solvents are recycled, and water is purged as a waste stream. All water streams containing DMSO and acetonitrile were remediated to more realistically estimate cost. A mean value of $0.11 \mathrm{kWh} \cdot \mathrm{m}^{-3}$ of wastewater was assumed with a projected installed cost of $15 \mathrm{M} \${ }^{6}$ Due to uncertainty regarding the true cost of wastewater remediation, sensitivity analysis was performed regarding the cost of remediating waste water, as well as the amount of water that was discharged. 
Site development and construction is assumed to take 9 months. Plant startup will occur over three months. Material costs during startup were added to the value of the initial capital loan. Table $\mathbf{S 2}$ shows the cash flow analysis parameters used in this analysis.

The plant will be constructed during the first year of the project life with start-up commencing in year two. A 15-day supply of DMSO, acetonitrile, and DEE would be purchased up-front to accommodate start-up. At steady state, the assumed recycling efficiency of acetonitrile and DMSO is $90 \%$, with $98 \%$ of diethyl ether being recycled. While these values were likely lower than a facility that meets federal and state waste generation regulations would operate at, overestimating high recovery values would artificially bias the minimum price point of HMF to a low value. All other capital costs were estimated using CAPCOST in Excel. ${ }^{7}$

Sensitivity analysis was performed using @ RISK (Palisade Software, Ithaca, NY, USA) software package. Table $\mathbf{S 3}$ shows the distributions used in sensitivity analysis. Program evaluation and review technique (PERT) distributions were used to define each variable in terms of a most likely, minimum, and maximum value. PERT distributions are a continuous distribution where the most likely value receives additional weight relative to the minimum and maximum values. Monte-Carlo analysis was performed to determine the sensitivity of financial returns to each variable. Cash flow evaluations were performed relative to the net present value (NPV) of benefits and costs over the 30-year operating life of the facility. An NPV greater than or equal to 0 is an investable project. The probability of the NPV being greater than or equal to 0 and the minimum HMF selling price to reach a mean NPV of 0 were evaluated in separate Monte-Carlo analysis with the same probability distributions. 
Table S1: Stream compositions for each of the flows in Figure 3. Reactor models only account for starch conversion in the reactor, and do not evaluate the fate of all components of corn.

\begin{tabular}{ccccccccccccc}
\hline Stream & $\mathbf{1}$ & $\mathbf{2}$ & $\mathbf{3}$ & $\mathbf{4}$ & $\mathbf{5}$ & $\mathbf{6}$ & $\mathbf{7}$ & $\mathbf{8}$ & $\mathbf{9}$ & $\mathbf{1 0}$ & $\mathbf{1 1}$ \\
& \multicolumn{8}{c}{ Component } \\
& Mass Flow (tonnes per day) & & \\
\hline Water & 0 & 0 & 456 & 2279 & 0 & 2279 & 1823 & 0 & 0 & 456 & 0 \\
DMSO & 0 & 0 & 114 & 2279 & 0 & 2279 & 2165 & 0 & 0 & 114 & 0 \\
ACN & 0 & 0 & 9 & 1797 & 1617 & 180 & 171 & 0 & 171 & 9 & 0 \\
DEE & 0 & 0 & 0 & 0 & 2549 & 0 & 0 & 2498 & 0 & 0 & 0 \\
HMF & 0 & 0 & 106 & 1024 & 918 & 106 & 0 & 0 & 0 & 106 & 918 \\
Maleic Acid & 0 & 0 & 3 & 33 & 0 & 33 & 30 & 0 & 0 & 3 & 0 \\
\hline AlCl3 & 0 & 0 & 14 & 136 & 0 & 136 & 122 & 0 & 0 & 14 & 0 \\
Salt & 0 & 0 & 208 & 2084 & 0 & 2084 & 1876 & 0 & 0 & 208 & 0 \\
\hline Corn Kernels & 2000 & 2000 & 0 & 0 & 0 & 0 & 0 & 0 & 0 & 0 & 0 \\
\hline
\end{tabular}

Table S2: Plant operation and construction assumptions for economic analysis.

\begin{tabular}{|l|l|}
\hline Plant Life & 30 years \\
\hline Discount Rate & $10 \%$ \\
\hline Depreciation & Straight Line, 10 year \\
\hline Federal Tax Rate & $35 \%$ \\
\hline Inflation & $2 \%$ \\
\hline Capital Cost & $43 \mathrm{M} \$$ \\
\hline Capital Cost + Start-up Materials & $180 \mathrm{M} \$$ \\
\hline Overhead Costs (Site development, piping) & $31 \mathrm{M} \$$ \\
\hline Portion Financed & $40 \%$ \\
\hline Loan Conditions & 10 years, 8\% APR \\
\hline Construction Period & 1 year \\
\hline Working Capital & $5 \%$ of total capital investment \\
\hline Start-up Period & 3 months \\
\hline \multicolumn{1}{|c|}{ Revenues during start-up } & $25 \%$ \\
\hline Variable costs during start-up & $100 \%$ \\
\hline \multicolumn{1}{|c|}{ Fixed costs during start-up } & $100 \%$ \\
\hline Annual Labor Cost & $11 \mathrm{M} \$$ per year \\
\hline
\end{tabular}

Table S3. PERT distribution parameters used for sensitivity analysis

\begin{tabular}{|l|l|l|l|l|}
\hline Variable & Min & Mode & Max & Reference \\
\hline Corn Cost [\$] & 3 & 3.75 & 7 & Average since 2015 \\
\hline Facility Uptime [\% of 350 day year] & $70 \%$ & $90 \%$ & $100 \%$ & Estimate \\
\hline HMF Yield [g HMF/g glucose] & $65 \%$ & $82 \%$ & $95 \%$ & Experimental Data \\
\hline HMF Selling Price [\$/tonne] & 900 & 1100 & 1200 & Competitive with PX cost $^{9}$ \\
\hline HMF Recovery Efficiency & $80 \%$ & $90 \%$ & $100 \%$ & Experimental Data \\
\hline Water Recycling \% & $80 \%$ & $90 \%$ & $95 \%$ & Calculated \\
\hline Acetonitrile Recycling \% & $90 \%$ & $95 \%$ & $99 \%$ & Estimate in ASPENPLUS \\
\hline
\end{tabular}




\begin{tabular}{|c|c|c|c|c|}
\hline DMSO Recycling \% & $90 \%$ & $95 \%$ & $99 \%$ & Estimate in ASPENPLUS \\
\hline DEE Recycling \% & $95 \%$ & $98 \%$ & $99 \%$ & Estimate in ASPENPLUS \\
\hline Water Treatment $\left[\$ / \mathrm{m}^{3}\right]$ & 0.07 & 0.11 & 0.15 & Estimate $^{6}$ \\
\hline
\end{tabular}

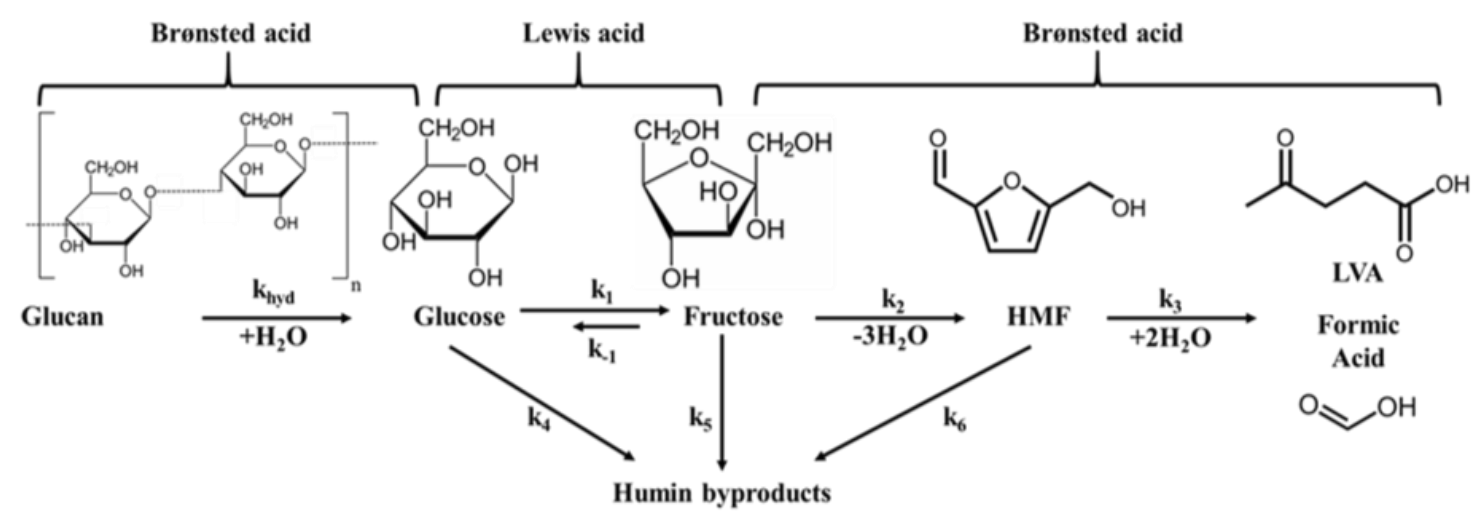

Figure S1: Reaction schematic for conversion of starch to HMF. Brønsted acid (maleic acid) catalyzes the hydrolysis of starch. $\mathrm{AlCl}_{3}$ (Lewis acid) catalyzes the isomerization of glucose to fructose. Fructose is then dehydrated to HMF, which can be rehydrated to form equimolar amounts of LVA and formic acid.

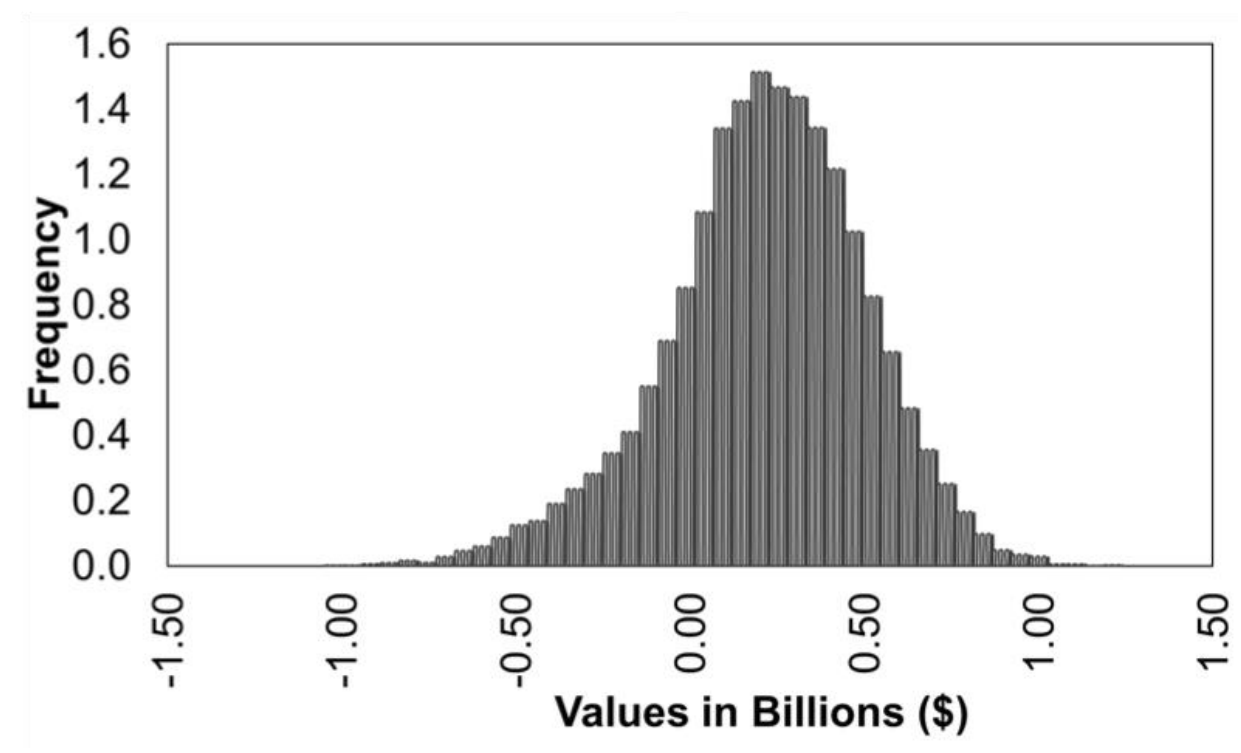

Figure S2. Probability distribution function of NPV for Monte Carlo analysis around analyzed distributions of input variables. In this analysis, there is an $80 \%$ chance of having a positive NPV, with a median NPV of $230 \mathrm{M} \$$ over the 30-year operating life of the facility.

\section{References for Supplemental Section}

(1) Yang, H.; Zhang, X.; Luo, H.; Liu, B.; Shiga, T. M.; Li, X.; Kim, J. I.; Rubinelli, P.; 
Overton, J. C.; Subramanyam, V.; et al. Overcoming Cellulose Recalcitrance in Woody Biomass for the Lignin-First Biorefinery. Biotechnol. Biofuels 2019, 12 (1).

https://doi.org/10.1186/s13068-019-1503-y.

(2) Zhang, X.; Murria, P.; Jiang, Y.; Xiao, W.; Kenttämaa, H. I.; Abu-Omar, M. M.; Mosier, N. S. Maleic Acid and Aluminum Chloride Catalyzed Conversion of Glucose to 5(Hydroxymethyl) Furfural and Levulinic Acid in Aqueous Media. Green Chem. 2016, 18 (19), 5219-5229. https://doi.org/10.1039/c6gc01395c.

(3) Overton, J. C.; Zhu, X.; Mosier, N. S. Molecular Dynamics Simulations and Experimental Verification to Determine Mechanism of Cosolvents on Increased 5Hydroxymethylfurfural Yield from Glucose. ACS Sustain. Chem. Eng. 2019, 7 (15), 12997-13003. https://doi.org/10.1021/acssuschemeng.9b02096.

(4) Altway, S.; Pujar, S. C.; de Haan, A. B. Liquid-Liquid Equilibria of Ternary and Quaternary Systems Involving 5-Hydroxymethylfurfural, Water, Organic Solvents, and Salts at 313.15 K and Atmospheric Pressure. Fluid Phase Equilib. 2018, 475, 100-110. https://doi.org/10.1016/j.fluid.2018.07.034.

(5) Alam, M. I.; De, S.; Khan, T. S.; Haider, M. A.; Saha, B. Acid Functionalized Ionic Liquid Catalyzed Transformation of Non-Food Biomass into Platform Chemical and Fuel Additive. Ind. Crops Prod. 2018, 123, 629-637. https://doi.org/10.1016/j.indcrop.2018.07.036.

(6) Running cost of wastewater treatment plant- CostWater.com.

(7) Turton, R. CAPCOST. Morgantown, West Virginia 2017.

(8) Corn Prices - 45 Year Historical Chart _ MacroTrends https://www.macrotrends.net/2532/corn-prices-historical-chart-data\%3ECorn Prices - 45 Year Historical Chart.

(9) Mellor, E. T. Para/Ortho-Xylenes (Europe) Para-Xylene Contract Prices. Independent Commodity Intelligence Services [Online], 2014.

https://www.icis.com/explore/commodities/chemicals/paraxylene-orthoxylene/asia/ (accessed April 20, 2019 